\title{
LONG-TERM EFFECTS OF NICOTINE ON RAT FUNGIFORM
} TASTE BUDS

\author{
S. TOMASSINI,a,b V. CUOGHI,a E. CATALANI,b G. CASINIb AND A. BIGIANIa* \\ aDipartimento di Scienze Biomediche, Università di Modena e Reggio Emilia, Via Campi 287, 41100 Modena, Italy \\ bDipartimento di Scienze Ambientali, Università della Tuscia, Largo dell'Università, blocco D, 01100 Viterbo, Italy \\ *Corresponding author. Tel:_39-059-205-5349; fax:_39-059-205-5363. \\ E-mail address: bigiani@unimore.it (A. Bigiani).
}

\begin{abstract}
Nicotine, an alkaloid found in tobacco smoke, has been recognized as capable of inducing changes in taste functionality in conditions of chronic exposure. The mechanisms underlying these sensory alterations, however, are currently unknown. We addressed this issue by studying the long-term effects of nicotine on the anatomical features of taste buds, the peripheral end-organs of taste, in rat fungiform papillae. Nicotine was administered to rats via drinking water over a period of 3 weeks, which represents a standard method to achieve chronic drug exposure in laboratory animals. We found that prolonged administration of nicotine induced a significant reduction in the size of fungiform taste buds, without affecting their total number on the rat tongue. Morphometric measurements as well as evaluations of taste cell membrane capacitance suggested that the reduced size of taste organs was determined by a decrease in the number of cells per taste bud. In addition, chronic treatment with nicotine caused an increase in the relative density of cells expressing gustducin, a specific $G$ protein _-subunit found in some taste cells and involved in bitter/sweet transduction. Interestingly, changes in the expression pattern of gustducin turned out to be more pronounced in periadolescent/adolescent than in adult rats. As a whole, our data indicate that long-term nicotine administration induces significant changes in the anatomical properties of taste buds in rat fungiform papillae. These changes could have a profound impact on the sensory information relayed to the brain; therefore, they may be responsible, at least in part, for the alterations in taste functionality observed during chronic nicotine exposure, a condition found in regular smokers. (C) 2007 IBRO. Published by Elsevier Ltd. All rights reserved.
\end{abstract}

Key words: gustation, morphology, immunohistochemistry, gustducin, membrane capacitance, smoking. 
Nicotine is an alkaloid found in tobacco smoke often used as chemical stimulus in taste research. Nicotine elicits a bitter taste sensation in humans (Pfaffmann, 1959), shares basic features with other bitter stimuli in monkeys (Scott et al., 1999), and induces aversive responses in hamsters (Brining et al., 1991). Recordings of neural activity from the glossopharyngeal and chorda tympani nerves in rat have shown that nicotine applied to the tongue stimulates gustatory afferent neurons (Dahl et al., 1997). Nicotine is represented as acid/bitter compound in rat neurons of the nucleus of solitary tract (Lemon and Smith, 2005). Finally, nicotine activates gustducin, a specific G protein found in taste cells and involved in bitter transduction (McLaughlin et al., 1992; Wong et al., 1996), in an in vitro assay (Ming et al., 1998, 1999). Besides the significance of these results for bitter taste, they clearly indicate that nicotine can interact with taste buds, the peripheral end-organs of taste (Witt et al., 2003).

As a taste stimulus, nicotine is usually applied for few seconds to the tongue mucosa, where taste buds are located, at millimolar concentrations (Dahl et al., 1997; Scott et al., 1999; Lemon and Smith, 2005; Simons et al., 2006). It is not known, however, whether nicotine affects taste buds during long periods of application, a condition commonly found in smokers. The continuous deliver of the drug through tobacco smoke keeps plasma nicotine at concentrations of about 60-300 nM (Benowitz, 1997; Benowitz et al., 2002; Teneggi et al., 2002; Patterson et al., 2003), and up to 10 _M in smoker saliva (Shafagoj et al., 2002; Teneggi et al., 2002). Taste buds are polarized sensory structures with an apical end bathed by saliva, and a basolateral region bathed by interstitial fluid in equilibrium with blood plasma (Witt et al., 2003). Thus, in smokers taste buds are continuously in contact with nicotine at nanomolar-micromolar concentrations. In other tissues, these levels of nicotine determine profound biological effects (reviewed in: Yildiz, 2004). Therefore, it is conceivable to hypothesize modifications in taste functionality in smokers. Indeed, several observations suggest that smoking or chronic administration of nicotine can alter the sense of taste in humans and laboratory animals. In regular smokers or people using smokeless tobacco, the ability to detect taste stimuli is impaired, as indicated by the increase in the threshold for recognition of taste stimuli (sweet, salty, sour, bitter) and by the reduction in the perceived intensity at supra-threshold concentrations (e.g. Grunberg, 1982; Mela, 1989; Pomerleau et al., 1991; Sato et al., 2002; Yamauchi et al., 2002). These taste alterations may impact food preference and feeding behavior. For example, sodium chloride (salty) hypogeusia (e.g. Baker et al., 1983; Raffaelli et al., 1989) may lead to increased consumption of saltier food in smokers, as reported by epidemiological studies (e.g. Tell et al., 1984; Woodward et al., 1994; Mediavilla Garcia et al., 2001). Taste alterations induced by smoking or chronic nicotine administration, and similar to those described in 
humans, have been documented also in rodents (e.g. Grunberg, 1982; Wager- Srdar et al., 1984; Etscorn et al., 1986; Parker and Doucet, 1995). The mechanisms underlying chronic changes in taste due to nicotine when present in the nanomolar-micromolar concentration range are not known. To address the issue of taste alterations induced by nicotine, we have begun to examine the longterm effects of sub-millimolar nicotine on the properties of taste buds and their cells. In other tissues, chronic nicotine exposure has been proven to induce anatomical changes, such as variation in cell number and/or in the density of specific cell types (e.g. Chen et al., 2003; Liu et al., 2005; Shingo and Kito, 2005; Carvalho et al., 2006). Therefore, here we focused our attention on the morphological characteristics of taste buds in control and in nicotine-treated rats. Specifically, in taste buds chronically exposed to nicotine, we performed an evaluation of taste bud morphometric parameters together with an analysis of the expression pattern of gustducin in whole-mount preparations of the rat fungiform papillae (e.g. Kim and Roper, 1995; Kretz et al., 1999). Several observations indicate that adolescent rats may differ from adult rats in the responses to chronic nicotine administration (e.g. Faraday et al., 2001, 2003; Schochet et al., 2004; Cruz et al., 2005). Accordingly, our analysis was performed on fungiform taste buds of both adolescent and adult rats. Finally, we performed some electrophysiological experiments with the patch-clamp technique to establish whether the cell membrane capacitance $(\mathrm{Cm})$, which is directly related to the taste cell size, was affected by nicotine treatment.

\section{EXPERIMENTAL PROCEDURES}

Experiments were performed in compliance with the Italian law on animal care No. 116/1992, and in accordance with the European Community Council Directive (EEC/609/86). All efforts were made to reduce both animal suffering and the number of animals used.

\section{Animals}

Male Sprague-Dawley rats were used in this study. Animals were housed two per cage on a 12-h light/dark cycle in climate-controlled conditions with ad libitum access to water and food. Animals were allowed to acclimate to their home cage for 4 days before the study began. We used three groups of rats according to their age at the beginning of the nicotine treatment: 24-day-old (periadolescent), 32-day-old (adolescent), and 49-day-old rats (adults). Adolescence is defined as the period spanning roughly 28-42 days, which corresponds to presexual maturation into young adulthood (Spear, 2000). We used both periadolescent and adolescent rats because postnatal development and maturation are quite rapid in laboratory rodents, with morphological and functional changes occurring in less than 1 week (e.g. Bigiani et al., 2002). At the end of 3-week 
nicotine administration (see below), animals had respectively 45, 53 and 70 days of age. Hereafter, we will refer to these age groups.

\section{Nicotine treatment}

Two common modes to achieve chronic nicotine exposure in laboratory animals are drug administration via drinking water or daily s.c. injections (e.g. Liu et al., 2005). In this study, we adopted the oral route because it allowed a more continuous exposure to nicotine, resembling the one observed in habitual smokers (Benowitz et al., 1982, 2002) or in subjects consuming "chewing tobacco" or "nicotine gum" (Mela, 1989; Parrott and Winder, 1989; Benowitz, 1997). Briefly, rats were then given free access to (_)nicotine bitartrate dehydrate (Sigma-Aldrich, Milan, Italy; 100 _g/mL, corresponding to about $200 \_$M of free nicotine) in their drinking water (tap water) or vehicle (100_ $\mathrm{g} / \mathrm{mL}$ tartaric acid) for 21 days. At the concentration used, nicotine does not represent a taste stimulus for rat (Simons et al., 2006). Nicotine solution intake was monitored every day to calculate the approximate concentration of drug ingestion $(\mathrm{mg} / \mathrm{kg} /$ day). On the basis of daily nicotine consumption and considering that most drinking takes place during rat active cycle from 19:00-07:00 h (Liu et al., 2005), we estimated a plasma nicotine concentration of about 20-30 $\mathrm{ng} / \mathrm{mL}$ plasma (corresponding to about 120-180 nM nicotine; see also: Liu et al., 2005), which is within the range achieved by habitual smokers (e.g. Benowitz et al., 1982, 2002; Teneggi et al., 2002).

\section{Whole-mount preparation}

Our procedure to obtain whole-mount preparation of the rat fungiform papillae closely followed published protocols (e.g. Kim and Roper, 1995; Doolin and Gilbertson, 1996; Kossel et al., 1997; Kretz et al., 1999). Briefly, at the end of the treatment period, rats were killed immediately, the tongue was removed and placed in ice-cold Tyrode solution consisting of (in mM): $140 \mathrm{NaCl}, 5$ $\mathrm{KCl}, 1 \mathrm{CaCl} 2,2 \mathrm{MgCl} 2,10$ glucose, 10 sodium pyruvate, and 10 Hepes, buffered to $\mathrm{pH}$ 7.4. The tongue was then injected between the lingual epithelium and the muscle layers with an enzyme cocktail containing: $1 \mathrm{mg}$ collagenase A (Roche Diagnostics, Monza, Italy), $2.5 \mathrm{mg}$ dispase II (Roche Diagnostics), $1 \mathrm{mg}$ trypsin inhibitor type I-S (Sigma) in $1 \mathrm{~mL}$ of Tyrode solution. The tongue was incubated in divalent-free Tyrode solution at room temperature $\left(20-22{ }^{\circ} \mathrm{C}\right)$ for $30-40$ min with air bubbling. After incubation, the lingual epithelium was peeled free from the underlying tissue with gentle dissection. The freed epithelium was pinned serosal side up in a Sylgard-lined Petri dish and inspected under dissecting microscope for the presence of fungiform taste buds (Fig. 1A). For morphological observations, whole-mounts were fixed with freshly prepared $4 \%$ paraformaldehyde in $0.1 \mathrm{M}$ phosphate buffer (PB), $\mathrm{pH} 7.4$ for $2 \mathrm{~h}$ at room temperature (Kim and 
Roper, 1995; Bigiani et al., 2002). Fixed whole-mounts were then transferred to $25 \%$ sucrose in 0.1 M PB and stored at $4{ }^{\circ} \mathrm{C}$.

\section{Taste bud cross-sectional area and cell population size}

Preliminary observations indicated that fungiform taste buds differed in cross-section size quite randomly across the surface tongue, although larger taste buds were often found in the most anterior part of the tongue (see also Krimm and Hill, 1998). To avoid that variations among animals could level off relevant differences between control and nicotine-treated rats, we proceeded as follows. Each tongue whole-mount was cut along the midline and each half was subdivided between the tip and the intermolar eminence into successive three regions of similar extension. Corresponding regions in control and nicotine-treated whole-mounts were then used to sample taste buds for morphological analysis. Taste bud cross-sectional area was evaluated as follows. Fixed wholemounts were washed in $0.1 \mathrm{M} \mathrm{PB}$ and mounted, serosal side up, onto gelatin-coated slides. The slides were then coverslipped in a $0.1 \mathrm{M} \mathrm{PB}-$ glycerin mixture and observed with a Zeiss miscroscope equipped with Nomarski optics (Carl Zeiss, Oberkochen, Germany). Note that in these conditions, taste buds were oriented perpendicularly to the slide plane. Single taste buds were then focused to the widest diameter, and images were acquired with a digital photocamera (Axiocam MRC; Zeiss) connected to the microscope. Maximal cross-sectional area was then calculated with the Zeiss Axio Vision 4 software. The number of cells occurring in maximum cross-section was used as an index of the cell population size in taste buds. To count taste cells, their nuclei were stained with propidium iodide 1:250 in

0.1 M PB (1-2 min incubation at room temperature). After staining, the lingual epithelium was rinsed, mounted onto gelatin-coated slides and coverslipped in a $0.1 \mathrm{M} \mathrm{PB}-$ glycerin mixture. The slides were then observed with a Leitz laser confocal scanning microscope, using a 100_objective (0.70 numerical aperture), laser power $20-30 \mathrm{~mW}$, and pinhole 1-3 AU. The confocal optical section containing the maximum transverse section of the taste bud was acquired and the digital image was sized and optimized for contrast and brightness using Adobe Photoshop 5.0 (Adobe Systems, Mountain View, CA, USA). The nuclear profiles were then counted. Note that although it would be possible to count all the cells in a taste bud after three-dimensional reconstruction, we found it more convenient for a large-scale analysis involving many taste buds ( $\left.n \_50\right)$ to use the above procedure.

\section{$\alpha$-Gustducin immunohistochemistry}

We used immunohistochemistry to determine the expression of $\alpha$-gustducin in fungiform taste buds. The whole mounts of the fungiform papillae were washed in $0.1 \mathrm{M} \mathrm{PB}$ and incubated for 2 days at 4 ${ }^{\circ} \mathrm{C}$ with the primary antibody (G_gust, 1:100; Santa Cruz Biotechnology, Santa Cruz, CA, USA) in 
$0.1 \mathrm{M}$ PB containing 5\% bovine serum albumin, 10\% normal goat serum and 1\% Triton X-100. Following washes in $0.1 \mathrm{M} \mathrm{PB}$, the whole-mounts were incubated in secondary antibody Alexa Fluor 488-conjugated goat anti-rabbit (dilution 1:200; Molecular Probes, Eugene, OR, USA), overnight at room temperature. Specificity of the immune reaction was assessed according to previous studies (Boughter et al., 1997; Cho et al., 1998). Control and nicotine-treated wholemounts were always processed in parallel to normalize for possible variations in staining from experiment to experiment. Immunofluorescence was examined with a Leitz laser confocal scanning microscope. To count the number of gustducin-positive cells in each taste bud, series of optical sections were acquired at 2-_m intervals and then viewed successively to identify stained cells in their entire length. Digital images from the confocal microscope were processed using Adobe Photoshop 5.0.

\section{$\mathbf{C m}$}

To evaluate $\mathrm{Cm}$, we applied the patch-clamp technique to single cells in isolated taste buds (Bigiani et al., 2002). Our procedure to isolate taste buds from the rat fungiform papillae in whole-mount preparations closely followed published protocols (e.g. Doolin and Gilbertson, 1996; Kossel et al., 1997). In whole-cell configuration, Cm was measured by integrating the capacitative current transient during application of a $10-\mathrm{mV}$ voltage step from a holding potential of _80 mV (for details, see Bigiani and Roper, 1993).

\section{Data analysis}

Analysis and plotting were performed using Prism 3.03 software (GraphPad Software, San Diego, USA). Results are presented as means_standard error of the means (S.E.M.). Data comparisons were made with a two-tailed unpaired $t$-test. For treatment_age interaction, statistical analysis was performed by means of the general linear model analysis of variance (statistical package SPSS version 10), considering $P \_0.05$ as a threshold for significant difference.

\section{RESULTS}

\section{Whole-mount preparations}

Whole-mount preparations of fungiform papillae (Fig. 1A) could be obtained easily from both nicotine-treated rats and control littermates. As shown in Fig. 1C, the total number of fungiform papillae was not affected by nicotine exposure in all age groups. On average, we counted about 178-184 papillae per tongue, in good agreement with previous estimations (Miller and Preslar, 1975).

\section{Morphometry of fungiform taste buds in nicotine-treated animals}


Taste buds are flask-shaped epithelial structures made of several, tightly packed cells (Fig. 1B). In the whole-mount preparation, their longitudinal axis is roughly perpendicular to the slide plane; when observed under light microscope, therefore, they appeared as round or ovoid (Fig. 1A). To obtain quantitative information on the size of fungiform taste buds, we measured the cross-sectional area at the widest point along the longitudinal axis. We preferred this morphometric parameter instead of the transverse diameter because often taste buds showed an elliptical profile instead of a circular one. Fig. 2A shows sample images of transverse, maximum section of a fungiform taste bud in a control rat (left) and in a nicotine-treated animal (right) taken from the same corresponding region of the tongue mucosa. It is evident from these images that cross-sectional surface was smaller in nicotine-treated buds than in control ones. This difference was observed for all age groups (Fig. 2B) and proved to be highly significant ( $\left.P \_0.0001\right)$. Interestingly, the percent reduction in crosssectional area in nicotine-treated taste buds tended to become larger, on average, with age: $13 \%, 16 \%$, and $21 \%$ reduction for 45-, 53-, and 70-day-old rats, respectively. A two-way analysis of variance revealed a significant treatment_age interaction $\left(\left[F(2,846) \_3,64 ; P \_0.027\right]\right.$ indicating an increase of nicotine effect with age.

As taste buds are flask-shaped rather than spherical or ovoid (Fig. 1B), their total volume is not easily calculated from the cross-section area at the widest point. We therefore estimated the length of their longitudinal axis by counting the number of confocal optical sections that included all successive, gustducin-immunoreactive (IR) cell profiles (Fig. 3A). As demonstrated previously by Boughter et al. (1997), gustducin-IR cells span through the entire length of taste buds. By sectioning some fungiform papillae, we confirmed that this was the case also in the whole-mount preparation (Fig. 1B). We found that the longitudinal axis was shorter in taste buds of nicotinetreated animals compared with controls in all age groups (Fig. 3B).

The number of nuclear profiles occurring in maximum cross-section tended to be smaller in nicotine-treated taste buds as compared with controls for all age-groups. The difference was highly significant for 53-day-old ( $\left.P \_0.002\right)$ and 70-day-old $\left(P \_0.005\right)$ rats (Fig. 4B). These data suggested that size differences between fungiform taste buds of nicotine-treated rats and those of control littermates were likely due to variation in the number of taste cells. This was further supported by the evaluation of cell packing density (nuclei/_m2), which was similar in nicotinetreated and in control taste buds for all age-groups: 0.029 vs. 0.031 in 45-day rats; 0.022 vs. 0.021 in 53-day rats; 0.020 vs. 0.020 in 70-day rats. These values were in good agreement with previously published data (Boughter et al., 1997).

\section{$\mathrm{Cm}$}


According to the measure of longitudinal axis, taste buds were shorter after nicotine exposure (Fig. 3B), suggesting that taste cells could be smaller. Observations of propidium iodide-stained profiles seemed to exclude this possibility; however only the cell nuclei are stained with this technique, and the use of this material to infer the size of whole cells may be misleading. To address this issue with a more accurate procedure, we measured the $\mathrm{Cm}$ of taste cells with the patch-clamp technique. $\mathrm{Cm}$ is directly related to the actual extension of the membrane lipid bilayer, and therefore it can be used to estimate the cell surface area in single as well as in coupled taste cells (Bigiani and Roper, 1993). We analyzed taste buds isolated from the fungiform papillae of 70-day-old animals (Fig. 5A), and found that $\mathrm{Cm}$ did not differ significantly among the two experimental groups (Fig. 5B), suggesting that chronic treatment with nicotine did not alter the average surface size of taste cells in fungiform papillae.

\section{Effect of chronic nicotine administration on gustducin expression}

The whole-mount preparation allowed us to visualize readily all the gustducin-expressing cells in single fungi fungiform

taste buds (Fig. 6). The percentage of fungiform taste buds found negative to gustducin immunostaining was about 6-10\% in both control and nicotine-treated animals. In labeled taste buds of 70-day-old rats, we found that the number of gustducin-IR cells did not change as a consequence of nicotine treatment (Fig. 6E, F). Mean values were 2.46_0.12 (n_100) in controls, and 2.53_0.12 (n_100) in animals exposed to nicotine. In young rats, on the contrary, fungiform taste buds contained a significantly larger number of gustducin-expressing cells when exposed to nicotine. For 45-day-old rats (Fig. 6A, B), we counted on average 2.95_0.13 (n_90) labeled cells per bud after nicotine treatment, whereas they were 2.60_0.13 (n_90) in controls $\left(P \_0.05\right)$. In 53dayold rats (Fig. 6C, D), labeled cells were 2.98_0.13 (n_80) after nicotine exposure, and 2.45_0.15 $\left(n \_80\right)$ in controls $\left(P \_0.02\right)$.

\section{DISCUSSION}

Our study was undertaken to obtain some insights on the effects of nicotine on fungiform taste buds when administered in chronic conditions and in the sub-millimolar range, therefore likely not acting as a taste stimulus. The main findings can be summarized as follows: 1) nicotine exposure reduces the size of taste buds by decreasing the number of taste cells; 2) nicotine alters the expression pattern of gustducin in taste buds; 3 ) some of these actions are related to the age of animals during the treatment period, being more prominent in adolescent rats than in adults. 
Our data clearly indicate that nicotine exposure affects the size of fungiform taste buds regardless of the age of animals (young vs. adult). Specifically, we found that both the maximal cross-sectional area and the longitudinal axis of nicotine-treated taste buds were significantly smaller than in controls. Two lines of evidence suggest that this difference was likely due to a reduction in the total number of cells per taste bud: the cell population size was constantly smaller in nicotine-treated taste buds as compared with control ones; the size of single taste cells did not change during nicotine treatment, as indicated by measuring their membrane capacitance with the patch-clamp technique. With the available data we cannot establish the mechanism by which nicotine affects the cell population size in taste buds. However, it is tempting to speculate that nicotine could interfere with the normal cell turnover. Taste buds consist of a renewing population of epithelial cells with a lifespan of about 10-14 days in fungiform and vallate papillae of the adult rat (Beidler and Smallman, 1965; Farbman, 1980; Hendricks et al., 2004). There are indications that nicotine may interfere with differentiation of tissue progenitor cells and cell proliferation with effects depending on cell types (reviewed in: Yildiz, 2004). These effects are thought to be mediated via activation of neuronal nicotinic acetylcholine receptors (nAChR), which occur in many non-neural cells (reviewed in Gotti and Clementi, 2004). Currently, there is no direct evidence for the expression of $\mathrm{nAChR}$ in taste cells. A recent electrophysiological study, however, indicates that the nicotinic antagonist mecamylamine applied to the tongue mucosa attenuates nicotinic excitation of neurons in the nucleus of solitary tract (Simons et al., 2006).

It is well established that in humans, on the anterior tongue, taste thresholds as well as taste suprathreshold sensitivity for sweet, bitter, sour, and salty stimuli are inversely related to the number/density of fungiform papillae (Miller and Reedy, 1990; Zuniga et al., 1993; Bartoshuk et al., 1994; Doty et al., 2001). In this study, we found that the number of fungiform papillae was not affected by chronic treatment with nicotine (Fig. 1C). The main effect of nicotine exposure was a marked reduction in the size of taste buds (Fig. 2B), likely due to a reduction in the total number of taste cells (Fig. 4B). How taste bud size can affect taste reception is difficult to establish with the available data. In rat fungiform papillae, taste bud size increases postnatally (Krimm and Hill, 1998) due to proliferation of taste cells (Kossel et al., 1997; Hendricks et al., 2004). In adult rat, there is a positive correlation between the taste bud size and the number of afferent fibers innervating fungiform taste buds (Krimm and Hill, 1998). This neuron/target match, however, is due to the increase in taste bud size with age and not to neural rearrangement (Krimm and Hill, 2000). It is therefore possible that, under nicotine treatment, a reduced number of taste cells per taste bud (presynaptic input) could determine a decrease in the activity of afferent nerve fibers (postsynaptic output), provided that the number of innervating fibers does not decrease. Further studies on the 
innervation pattern of single fungiform taste buds during nicotine chronic administration may provide some insights into this issue.

\section{Effect of nicotine on gustducin expression}

Chronic treatment with nicotine induced a significant increase in the number of gustducin-IR cells in taste buds of young rats, but not in the adults. Variations in the number of gustducin- IR cells in different taste bud populations could be due to changes in the total number of cells inside taste buds. In particular, an increase in gustducin-IR cells could be simply correlated to an increase in the size of taste buds (Bigiani et al., 2002; Zhang et al., 2006). However, we found that the number of taste bud cells tended to decrease after nicotine treatment (see Fig. 4). Therefore, a larger number of gustducin- IR cells in nicotine-treated, young rats was not due to a size factor. Interestingly, nicotine exposure did not affect significantly the number of labeled cells per bud in adult rats, despite the reduction in the cell population size. We therefore evaluated the ratio between the average value of the number of gustducin-IR cells per taste bud and the value of the cell population size for each age group. The data are shown in Fig. 7 and indicate that the density of labeled cells was higher in taste buds exposed to nicotine at all tested ages, including adults. The mechanism by which nicotine promotes the increase in the density of gustducin-IR cells remains to be elucidated. Gustducin has been implicated in the transduction of both sweet- and bitter-tasting substances (Wong et al., 1996). There is a correlation between the number/density of gustducin-expressing cells in a given taste bud population and its sensitivity to taste stimuli: the more extensive is the gustducin labeling, the more sensitive taste buds are to sweet or bitter stimuli (Boughter et al., 1997). It is therefore tempting to speculate that the nicotine-induced increase in the gustducin-IR cells density in rat fungiform taste buds might increase their sensitivity to sweet or bitter stimuli. However, several studies indicate that that smoking or chronic nicotine tends to reduce, rather than increase, sweet and bitter sensitivity (e.g. Yamauchi et al., 2002; Sato et al., 2002). We do not know how to explain this discrepancy at the moment. It would be of interest to evaluate whether sweet/bitter substances induce an increase in the activity in the nerve fibers leaving fungiform taste buds in nicotine-treated rats.

\section{Age-related effects of nicotine}

Several studies indicate that the effects of chronic exposure to nicotine may differ in adolescent vs. adult rats (e.g. Faraday et al., 2001, 2003; Schochet et al., 2004; Cruz et al., 2005). We found that the effect of nicotine exposure on taste bud size was similar in both periadolescent/adolescent and adult rats, although tended to increase with age. In contrast, the effect on gustducin expression depended on the animal age, with a more pronounced response to this drug only in young rats (see Figs. 6 and 7). These findings suggested that nicotine exerted distinct actions on the 
molecular/cellular processes underlying the regulation of taste bud size and of the number/density of gustducinexpressing cells. More importantly, our findings support the view that periadolescents and adolescents may be particularly vulnerable to nicotine's effect, displaying different long-term responses to nicotine than adults. The impact of these age-related effects of nicotine on taste system will require further functional studies to be fully understood.

\section{Whole-mount preparation vs. tissue sections}

The whole-mount preparation of taste papillae has been used previously to establish the distribution pattern of immunolabeled cells in single taste buds (Kim and Roper, 1995; Kretz et al., 1999; Bigiani et al., 2002). To our knowledge, this is the first study in which the whole-mount preparation of taste papillae is used for morphometric analysis of taste buds, which is usually performed on tissue sections. To obtain the whole-mounts, the epithelial layer bearing taste buds has to be detached, after enzymatic treatment, from the underlying lamina propria of the tongue mucosa, and taste buds become freed from surrounding connective tissue prior to fixation (see Fig. 1A, B). Therefore, concerns could be raised on the preservation of anatomical features of taste buds in the whole-mount preparation. A comparison of our findings with published data on tissue sections supports the validity of the whole-mounts as preparation for morphometric analysis of fungiform taste buds. For example, Boughter et al. (1997) reported an average value of about $40 \_m$ for the transverse diameter of taste buds in sections of fungiform papillae in adult male rats. By using the formula for the area of a circle and the average value we measured for the cross-sectional area in control, 70-day rats, we obtained an average circle diameter of 44 _m, in good agreement with measurements by Boughter and collaborators.

Acknowledgments-We wish to thank Dr. Federica Paoletti for support in the early phase of this work, and Dr. Bernd Lindemann for technical advice. We also thank Dr. Gabriella Gambellini, Dr. Elisa Ovidi, and Giuseppe Nespoli for excellent technical assistance. This work was supported by Philip Morris USA Inc. and by Philip Morris International.

\section{REFERENCES}

Baker KA, Didcock EA, Kemm JR, Patrick JM (1983) Effect of age, sex and illness on salt taste detection thresholds. Age Ageing 12:159-165.

Bartoshuk LM, Duffy VB, Miller IJ (1994) PTC/PROP tasting: anatomy, psychophysics, and sex effects. Physiol Behav 56:1165-1171.

Beidler LM, Smallman R (1965) Renewal of cells within taste buds. J Cell Biol 27:263-272. 
Benowitz NL, Florence K, Jacob P III (1982) Circadian blood nicotine concentrations during cigarette smoking. Clin Pharmacol Ther 32:758-764.

Benowitz NL (1997) Systemic absorption and effects of nicotine from smokeless tobacco. Adv Dent Res 11:336-340.

Benowitz NL, Hansson A, Jacob P III (2002) Cardiovascular effects of nasal and transdermal nicotine and cigarette smoking. Hypertension 39:1107-1112.

Bigiani A, Cristiani R, Fieni F, Ghiaroni V, Bagnoli P, Pietra P (2002) Postnatal development of membrane excitability in taste cells of the mouse vallate papilla. J Neurosci 22:493-504.

Bigiani A, Roper SD (1993) Identification of electrophysiologically distinct cell subpopulations in Necturus taste buds. J Gen Physiol 102:143-170.

Boughter Jr JD, Pumplin DW, Yu C, Christy RC, Smith DV (1997) Differential expression of _gustducin in taste bud populations of the rat and hamster. J Neurosci 17:2852-2858.

Brining SK, Belecky TL, Smith DV (1991) Taste reactivity in the hamster. Physiol Behav 49:12651272.

Carvalho CAF, Favaro WJ, Padovani CR, Cagnon VHA (2006) Morphometric and ultrastructure features of the ventral prostate of rats (Rattus norvegicus) submitted to long-term nicotine treatment. Andrologia 38:142-151.

Chen W-JA, Edwards RB, Romero RD, Parnell SE, Monk RJ (2003) Long-term nicotine exposure reduces Purkinje cell number in the adult rat cerebellar vermis. Neurotoxicol Teratol 25:329-334. Cho YK, Farbman AI, Smith DV (1998) The timing of alpha-gustducin expression during cell renewal in rat vallate taste buds. Chem Senses 23:735-742.

Cruz FC, Delucia R, Planeta CS (2005) Differential behavioral and neuroendocrine effects of repeated nicotine in adolescent and adult rats. Pharmacol Biochem Behav 80:411-417.

Dahl A, Erickson RP, Simon SA (1997) Neural responses to bitter compounds in rats. Brain Res 756:22-34.

Doolin RE, Gilbertson TA (1996) Distribution and characterization of functional amiloridesensitive sodium channels in rat tongue. J Gen Physiol 107:545-554.

Doty RL, Bagla R, Morgenson M, Mirza N (2001) NaCl thresholds: relationship to anterior tongue locus, area of stimulation, and number of fungiform papillae. Physiol Behav 72:373-378.

Etscorn F, Moore GA, Hagen LS, Caton TM, Sanders DL (1986) Saccharin aversions in hamsters as a result of nicotine injections. Pharmacol Biochem Behav 24:567-570.

Faraday MM, Elliott BM, Grunberg NE (2001) Adult vs. adolescent rats differ in biobehavioral responses to chronic nicotine administration. Pharmacol Biochem Behav 70:475-489. 
Faraday MM, Elliott BM, Phillips JM, Grunberg NE (2003) Adolescent and adult male rats differ in sensitivity to nicotine's activity effects. Pharmacol Biochem Behav 74:917-931.

Farbman AI (1980) Renewal of taste bud cells in rat circumvallate papillae. Cell Tissue Kinet 13:349-357.

Gotti C, Clementi F (2004) Neuronal nicotinic receptors: from structure to pathology. Prog Neurobiol 74:363-396.

Grunberg NE (1982) The effects of nicotine and cigarette smoking on food consumption and taste preferences. Addict Behav 7:317-331.

Hendricks SJ, Brunjes PC, Hill DL (2004) Taste bud cell dynamics during normal and sodiumrestricted development. J Comp Neurol 472:173-182.

Kim DJ, Roper SD (1995) Localization of serotonin in taste buds: a comparative study in four vertebrates. J Comp Neurol 353:364-370.

Kossel AK, McPheeters M, Lin W, Kinnamon SC (1997) Development of membrane properties in taste cells of fungiform papillae: functional evidence for early presence of amiloride-sensitive sodium channels. J Neurosci 17:9634-9641.

Kretz O, Barbry P, Bock R, Lindemann B (1999) Differential expression of RNA and protein of the three pore-forming subunits of the amiloride-sensitive epithelial sodium channel in taste buds of the rat. J Histochem Cytochem 47:51-64.

Krimm RF, Hill DL (1998) Innervation of single fungiform taste buds during development in rat. J

Comp Neurol 398:13-24.

Krimm RF, Hill DL (2000) Neuron/target matching between chorda tympani neurons and taste buds during postnatal rat development. J Neurobiol 43:98-106.

Lemon CH, Smith DV (2005) Neural representation of bitter taste in the nucleus of the solitary tract. J Neurophysiol 94:3719-3729.

Liu J-J, Mohila CA, Gong Y, Govindarajan N, Onn S-P (2005) Chronic nicotine exposure during adolescence differentially influences calcium- binding proteins in rat anterior cingulated cortex. Eur J Neurosci 22:2462-2474.

McLaughlin SK, McKinnon PJ, Margolskee RF (1992) Gustducin is a taste-cell-specific G protein closely related to the transducins. Nature 357:563-569.

Mediavilla Garcia JD, Fernandez Torres C, Aliaga Martinez L, Leon Ruiz L, Sabio Sanchez M, Jimenez Alonso J (2001) Clinical characteristics of patients with essential hypertension regarding salt intake. Rev Clin Esp 201:627-631.

Mela DJ (1989) Gustatory function and dietary habits in users and nonusers of smokeless tobacco. Am J Clin Nutr 49:482-489. 
Miller IJ Jr, Preslar AJ (1975) Spatial distribution of rat fungiform papillae. Anat Rec 181:679-684. Miller IJ Jr, Reedy FE Jr (1990) Variations in human taste bud density and taste intensity perception. Physiol Behav 47:1213-1219.

Ming D, Ruiz-Avila L, Margolskee RF (1998) Characterization and solubilization of bitterresponsive receptors that couple to gustducin. Proc Natl Acad Sci U S A 95:8933-8938. Ming D, Ninomiya Y, Margolskee RF (1999) Blocking taste receptor activation of gustducin inhibits gustatory responses to bitter compounds. Proc Natl Acad Sci U S A 96:9903-9908. Parker LA, Doucet K (1995) The effects of nicotine and nicotine withdrawal on taste reactivity. Pharmacol Biochem Behav 52:125-129.

Parrott AC, Winder G (1989) Nicotine chewing gum (2 mg, $4 \mathrm{mg}$ ) and cigarette smoking: comparative effects upon vigilance and heart rate. Psychopharmacology 97:257-261.

Patterson F, Benowitz N, Shields P, Kaufmann V, Jepson C, Wileyto P, Kucharski S, Lerman C (2003) Individual differences in nicotine intake per cigarette. Cancer Epidemiol Biomarkers Prev $12: 468-471$.

Pfaffmann C (1959) The sense of taste. In: Handbook of physiology: Neurophysiology, Vol. 1 (Field J, Magoun HW, Hall VE, eds), pp 507-533. Washington, DC: American Physiological Society.

Pomerleau C, Garcia AW, Drewnowski A, Pomerleau OF (1991) Sweet taste preference in women smokers: comparison with nonsmokers and effects of menstrual phase and nicotine abstinence. Pharmacol Biochem Behav 40:995-999.

Raffaelli R, Baldinetti A, Somma F, Rumi G, Tiberi F (1989) Variazioni della funzione gustativa nei soggetti fumatori. Minerva Stomatol 38:1253-1256.

Sato K, Endo S, Tomita H (2002) Sensitivity of three loci on the tongue and soft palate to four basic tastes in smokers and non-smokers. Acta Otolaryngol Suppl 546:74-82.

Schochet TL, Kelley AE, Landry CF (2004) Differential behavioral effects of nicotine exposure in adolescent and adult rats. Psychopharmacology 175:265-273.

Scott TR, Giza BK, Yan J (1999) Gustatory neural coding in the cortex of the alert cynomolgus macaque: the quality of bitterness. J Neurophysiol 81:60-71.

Shafagoj YA, Mohammed FI, Hadidi KA (2002) Hubble-bubble (water pipe) smoking: levels of nicotine and cotinine in plasma, saliva and urine. Int J Clin Pharmacol Ther 40:249-255. Shingo AS, Kito S (2005) Effects of nicotine on neurogenesis and plasticity of hippocampal neurons. J Neural Transm 112:1475-1478.

Simons CT, Boucher Y, Carstens MI, Carstens E (2006) Nicotine suppression of gustatory responses of neurons in the nucleus of the solitary tract. J Neurophysiol 96:1877-1886. 
Spear LP (2000) The adolescent brain and age-related behavioral manifestations. Neurosi Biobehav Rev 24:417-463.

Tell GS, Klepp KI, Vellar OD, McAlister A (1984) Preventing the onset of cigarette smoking in Norwegian adolescents: the Oslo Youth Study. Prev Med 13:256-275.

Teneggi V, Squassante L, Iavarone L, Milleri S, Bye A, Gomeni R (2002) Correlation and

predictive performance of saliva and plasma nicotine concentration on tobacco withdrawal-induced craving. Br J Clin Pharmacol 54:407-414.

Wager-Srdar SA, Levine AS, Morley JE, Hoidal JR, Niewoehner DE (1984) Effects of cigarette smoke and nicotine on feeding and energy. Physiol Behav 32:389-395.

Witt M, Reutter K, Miller IJ Jr (2003) Morphology of the peripheral taste system. In: Handbook of olfaction and gestation (Doty RL, ed), pp 651-677. New York: Marcel Dekker.

Wong GT, Gannon KS, Margolskee RF (1996) Transduction of bitter and sweet taste by gustducin. Nature 381:796-800.

Woodward M, Bolton-Smith C, Tunstall-Pedoe H (1994) Deficient health knowledge, diet, and other lifestyles in smokers: is a multifactorial approach required? Prev Med 23:354-361.

Yamauchi Y, Endo S, Yoshimura I (2002) A new whole-mouth gustatory test procedure. II. Effects of aging, gender and smoking. Acta Otolaryngol Suppl 546:49-59.

Yildiz D (2004) Nicotine, its metabolism and an overview of its biological effects. Toxicon 43:619632.

Zhang GH, Deng SP, Li LL, Li HT (2006) Developmental change of alpha-gustducin expression in the mouse fungiform papilla. Anat Embryol 211:625-630.

Zuniga JR, Davis SH, Englehardt RA, Miller IJ Jr, Schiffman SS, Phillips C (1993) Taste performance on the anterior human tongue varies with fungiform taste bud density. Chem Senses 18:449-460.

Figure legends

Fig. 1. Whole-mount preparation of rat fungiform taste buds. (A) Epithelial tissue observed from the serosal side. Circular area indicates the position of fungiform papillae. Single taste buds can be readily distinguished as small spheres inside the fungiform area (arrow). Scale bar_150_m. (B) Coronal section of a fungiform taste bud in whole-mount preparation observed with Nomarski optics (left) and with Nomarski optics merged with the gustducin immunofluorescence image of the same field. Note that the gustducin-expressing cells span the entire length of taste buds. The dark 
color of gustducin immunofluorescence derives from the merging procedure used in Photoshop, which has been chosen to increase contrast of immunolabeling against the background. Scale bar_10_m. (C) Number of fungiform papillae occurring in whole-mounts from control (CON) and nicotinetreated (NIC) rats ( $n \_3-4$ tongues for each age/experimental group).

Fig. 2. Maximal cross-sectional area of fungiform taste buds. (A) Fungiform taste buds observed with Nomarski optics in wholemount preparations. The partially out-of-focus contour of the papilla is visible around the taste buds, where individual taste cells can be seen. Both images are taken from 53-day rats (left, control; right, nicotinetreated). Scale bar_20_m. (B) Average values of cross-sectional area in control (CON) and nicotine-treated (NIC) rats. Number of observations: 90/135/135 (3 to 4 whole-mounts for each age/experimental group). Asterisks indicate significant difference (two-tailed test, $\left.P \_0.0001\right)$.

Fig. 3. Longitudinal axis of fungiform taste buds. (A) Procedure adopted to estimate the axis length from the observations of gustducin- positive cell profiles. (B) Average values of longitudinal axis in control (CON) and nicotine-treated (NIC) rats. Number of observations for each age/experimental groups: 50 taste buds ( 2 to 3 whole-mounts for each age/experimental group). Asterisks indicate significant difference (two-tailed test: $P \_0.02$ for 45 -day rats; $P \_0.01$ for 53 -day rats; $P \_0.05$ for 70-day rats).

Fig. 4. Cell population size in fungiform taste buds. (A) Propidium iodide-stained nuclei in taste buds of control (left) and nicotine-treated (right) 53-day rats. Stained nuclei in the rim of the papilla can also be seen in both images. Scale bar_10_m. (B) Average values of total number of stained nuclei per maximal cross-section in control (CON) and nicotine-treated (NIC) rats. Number of observations for each age/experimental group: 60 taste buds (three whole-mounts for each age/experimental group). Asterisks indicate significant difference (twotailed test: $P \_0.002$ for 53day rats; $P \_0.005$ for 70 -day rats).

Fig. 5. Membrane capacitance of taste cells in fungiform taste buds. (A) Differential interference contrast photomicrograph depicting a taste bud isolated from fungiform papilla of 70-day-old rat. Arrow indicates apical pole. Scale bar_5 _m. (B) Cm measured in fungiform taste cells from control rats ( 31 cells) and nicotine-treated littermates (50 cells). Mean values were not significantly different (two-tailed test, $P \_0.5$ ). 
Fig. 6. Gustducin-IR taste cells in rat fungiform taste buds. (A-F) Confocal images (single optical sections) showing gustducin-IR taste cells in taste buds of whole-mounts from control and nicotinetreated animals. Note that the immunostaining is confined at or near the cell membrane, in accordance with the cellular localization of the $\mathrm{G}$ protein gustducin. A and B show control and nicotine-treated taste buds, respectively, in 45-day rats; $\mathrm{C}$ and $\mathrm{D}$ in 53-day rats; $\mathrm{E}$ and $\mathrm{F}$ in 70 -day rats. Scale bar_10_m. (G) Quantitative evaluation of the number of gustducin-IR cells per each taste bud in control (CON) and nicotinetreated (NIC) animals. Number of observations: 90/60/100 (4 to 5 whole-mounts for each age/experimental group). Asterisks indicate significant difference (two-tailed test: $P \_0.05$ for 45 -day rats; $P \_0.02$ for 53-day rats).

Fig. 7. Effect of chronic treatment with nicotine on the density of gustducin-IR cells in fungiform taste buds. Density values were obtained by evaluating the ratio between the number of gustducinpositive cells occurring in single taste buds and the estimated number of taste bud cells. Mean values from Figs. 4 and 6 were used for this analysis. CON, control rats; NIC, nicotine-treated rats. 
A

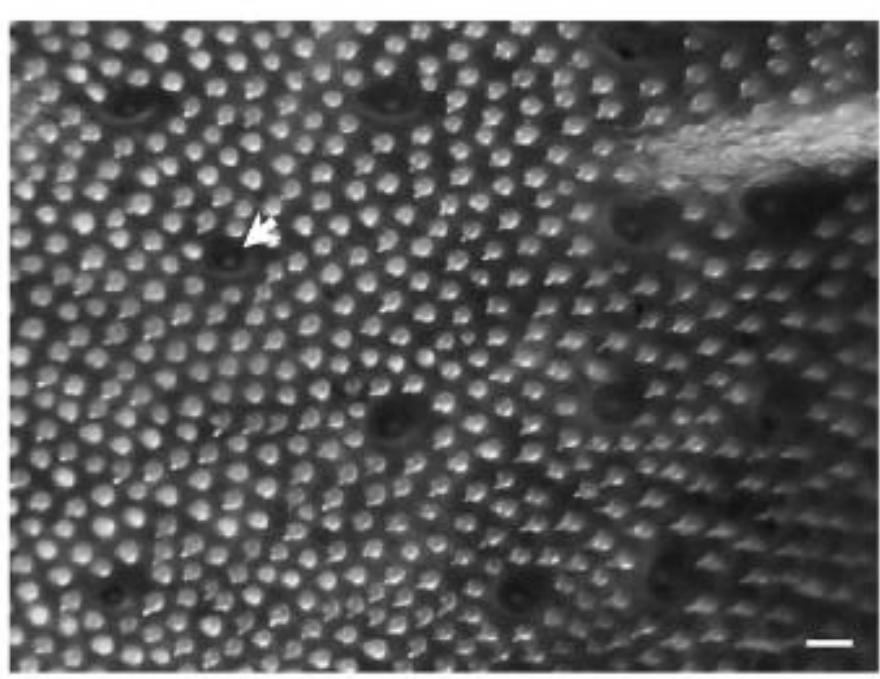

B

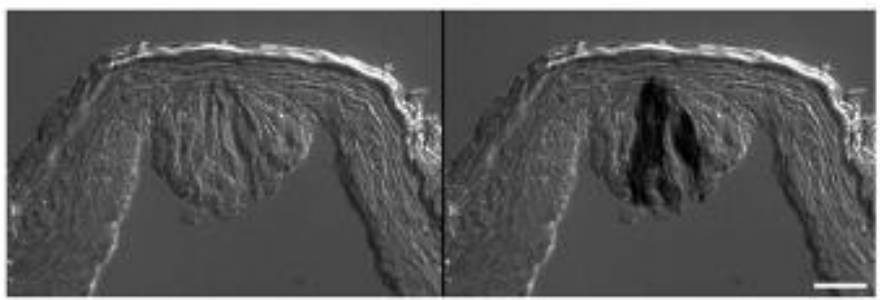

C Number of fungiform papillae / tongue
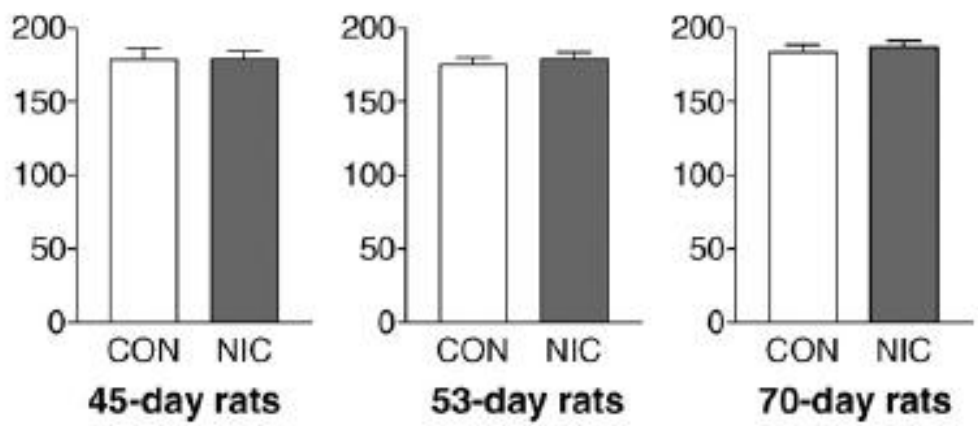

Fig.1 
A
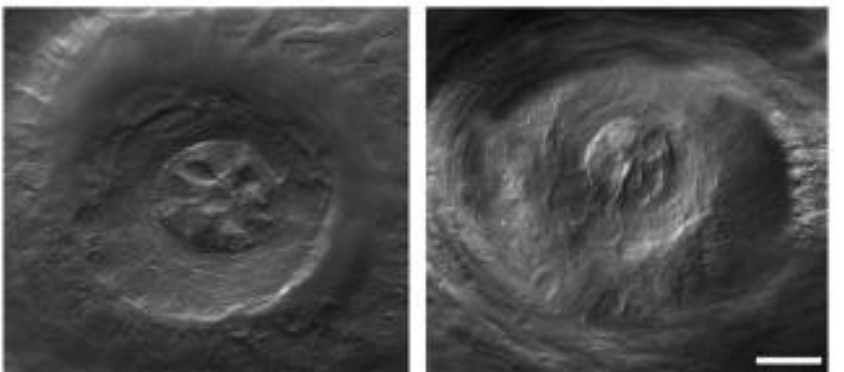

B

Cross-sectional area $\left(\mu \mathrm{m}^{2}\right)$
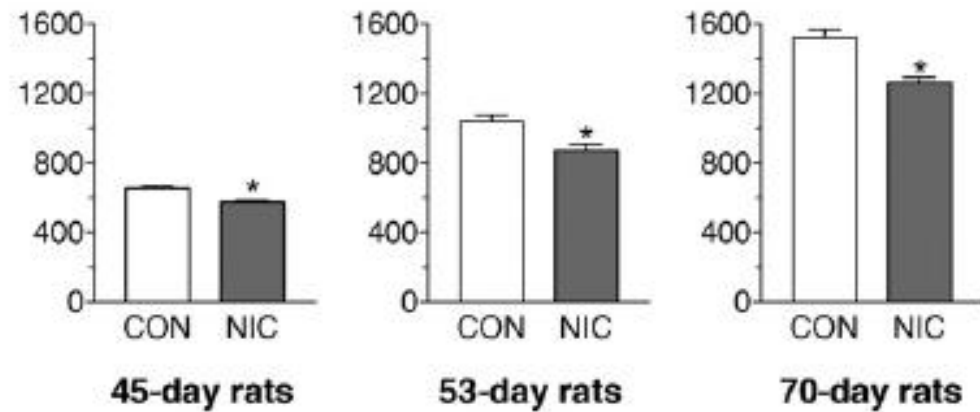

45-day rats

53-day rats

70-day rats

Fig.2 
A

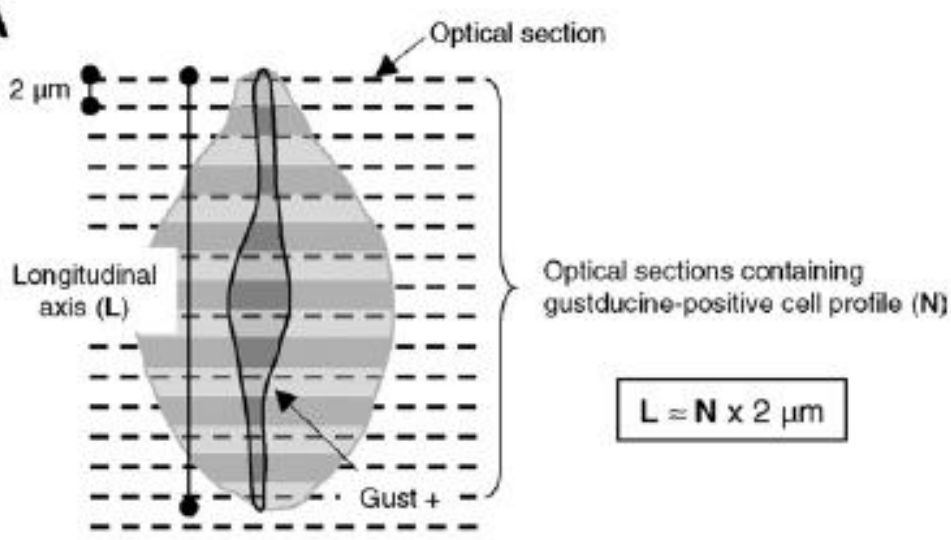

B

Longitudinal axis $(\mu \mathrm{m})$
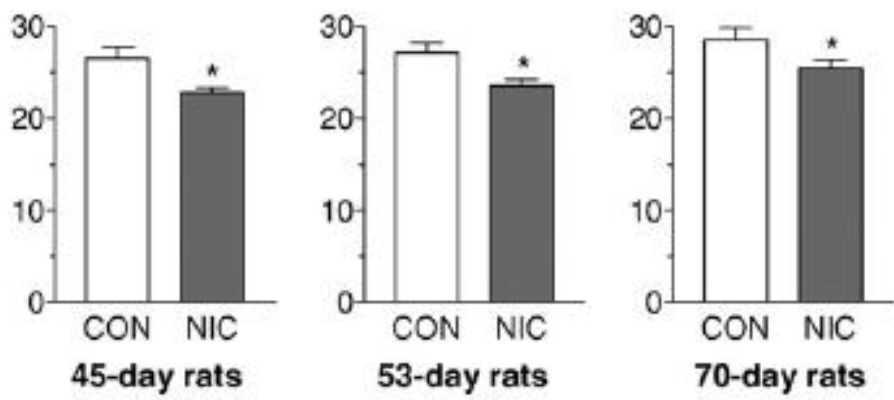

Fig.3 
A
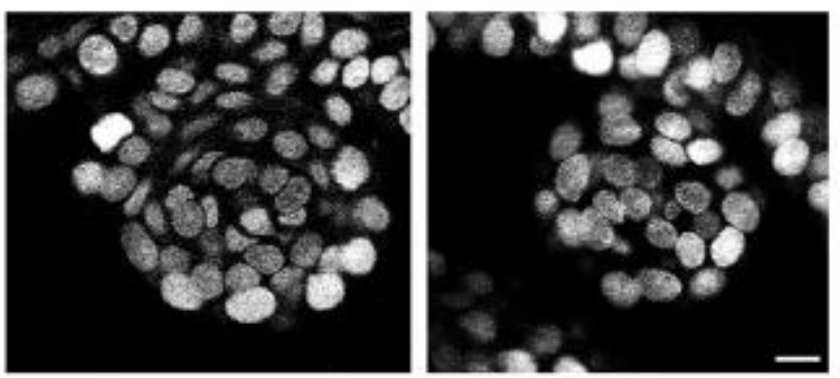

B

Number of nuclei / max cross-section

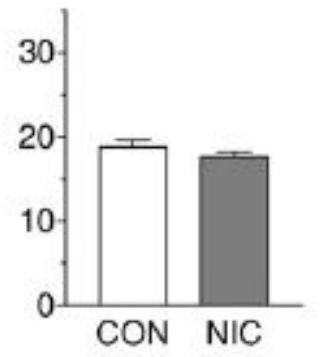

45-day rats

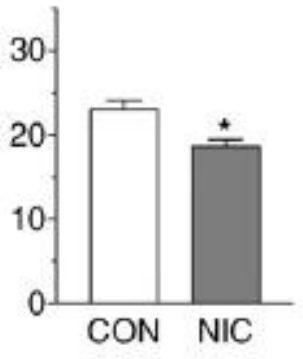

53-day rats

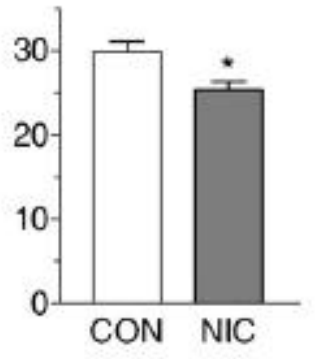

70-day rats

Fig.4 

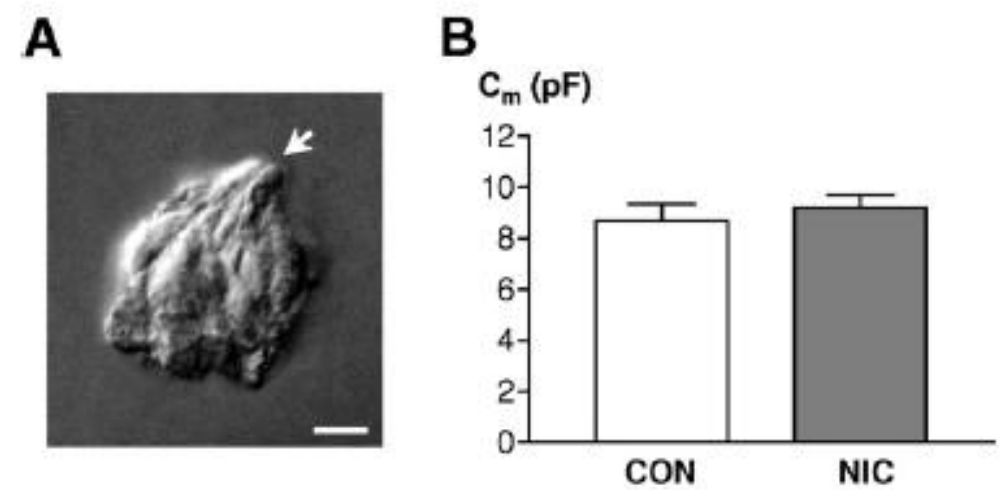

Fig.5 


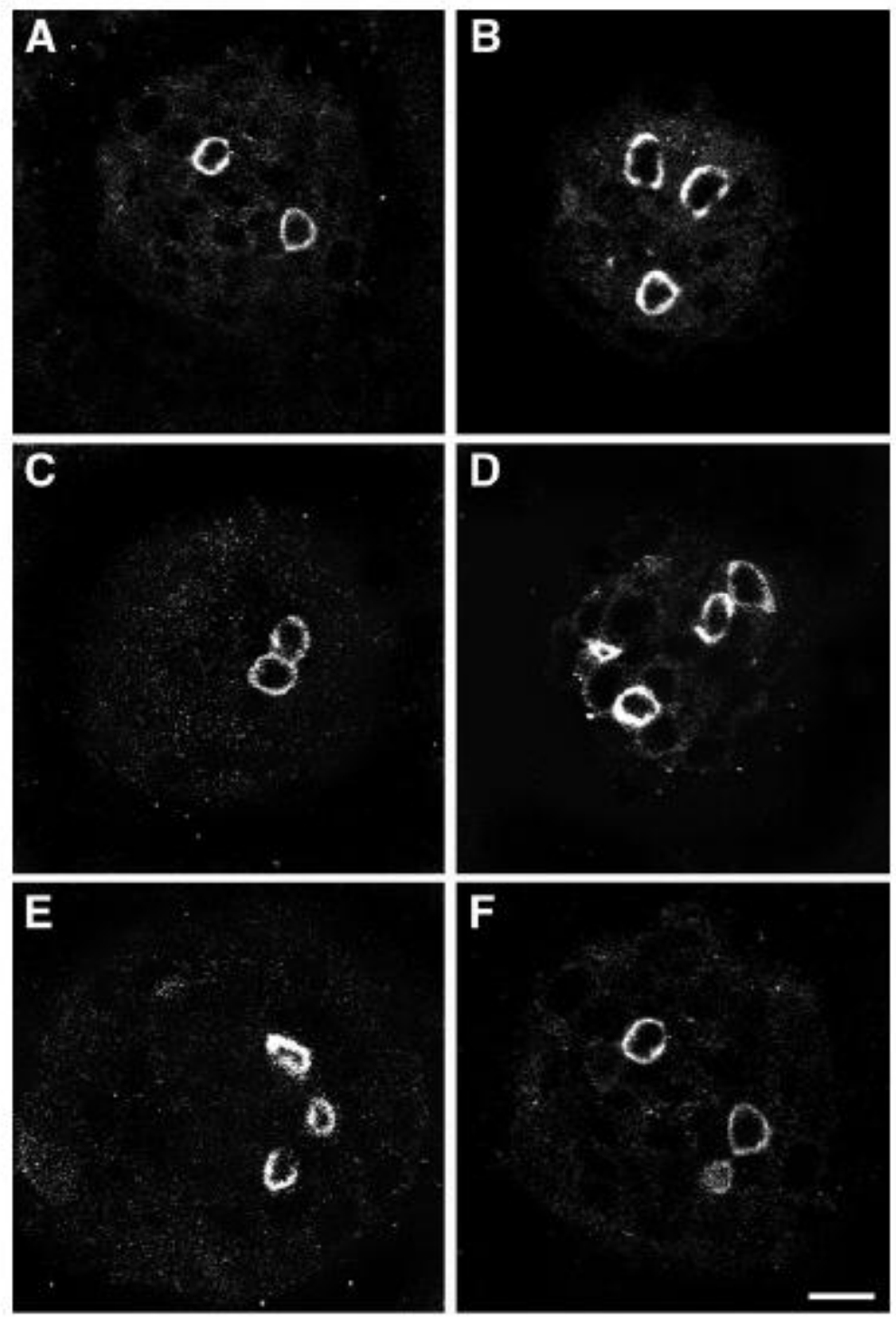

G Number of gustducin-positive cells / taste bud
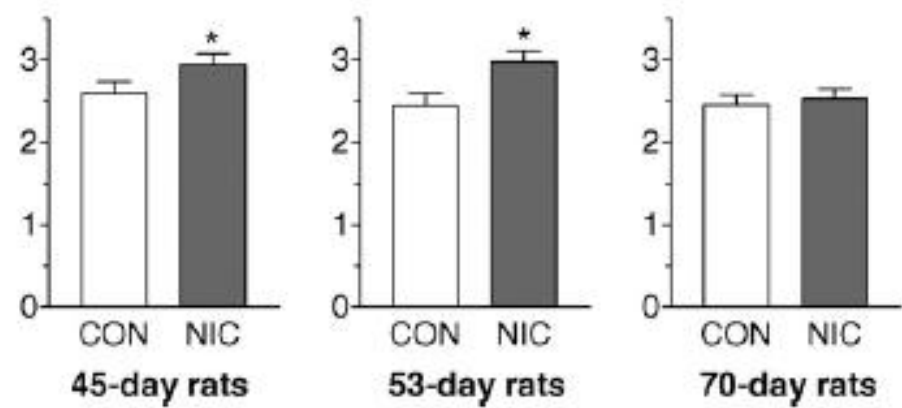

Fig.6 


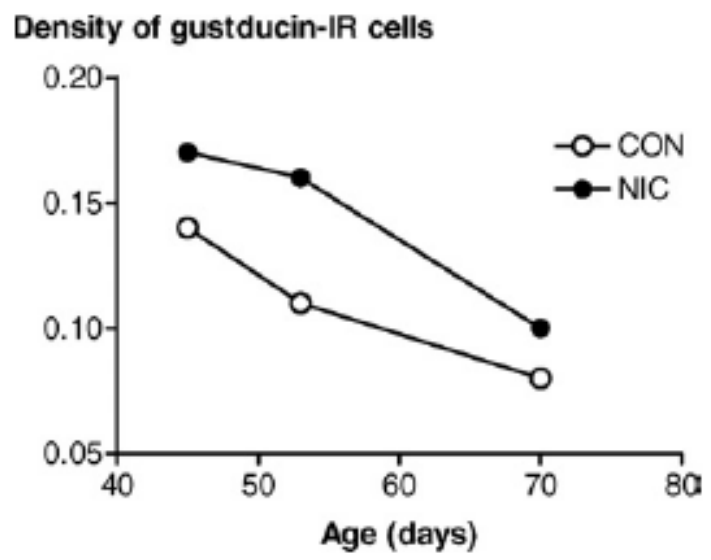

Fig.7 